\title{
Demystifying the Dabbawallahs: India's Lean Food Delivery Operations Explained with Operations Management Practices
}

\author{
Kumaraguru Mahadevan \\ Central Queensland University, Australia \\ Email: k.mahadevan@cqu.edu.au
}

\begin{abstract}
The Dabbawallahs have been delivering home-cooked lunches to office workers in Mumbai, India, since 1890. There is a lot written about their success that the led to six sigma certification of their flawless service. Some authors have contradicted this certification. On the contrary, there may be other factors that keep the Dabbawallahs in the limelight. However, there are inadequate discussions about which aspects of their operations underpin their success. This research revealed that Dabbawallah operations could be interpreted with various concepts and theories. They include organisational culture, operations management tools, theories, operational strategies, techniques (JIT), and tools (LEAN and SMED). Moreover, Dabbawallahs are a cultural icon in Mumbai powered by their branding. However, it does not clear which of the concepts, practices, and theories impacts the Dabbawallah operations. The author conceptualised the "Dabbawallah four forces" model incorporating four components: cultural branding; organisation culture; strategy; and six sigma based on LEAN tool (PDCA). The cultural branding is the inertia in the food delivery operations that leads to achieving six sigma or operational excellence which in turn further powers its branding. Overall, the Dabbawallahs run a LEAN food delivery operation powered by its branding and are teaching big corporations about simplicity.
\end{abstract}

Keywords: LEAN, branding, supply chain integration, SMED, organisation culture

\section{INTRODUCTION}

Organisations strive for operational excellence and performance to meet the ever-changing demands of customers and are a part of the global supply chain (SC) networks sharing information with SC partners (Mangla,2020; Mahadevan, 2013). Information sharing is the way for bridging the fragmented SC (Kritchanchai, 2012). Land Rover Jaguar, owned by Tata Motors, has its corporate office in Mumbai, India, design office in the United Kingdom, and manufacturing globally managed with best practices in operations management. Yet, Tata, FedEx, and Amazon have sent their executives to Mumbai to study the Dabbawallah operations that deploy limited resources and no technology apart from mobile phones in delivering lunches to office workers since 1890 (Pathak 2010: Pilling and Chilkoti 2015). Interestingly, Indian scholars presently have more interest in learning the management techniques from foreign presentations rather than going for the renaissance of oriental Indian management systems (Rath et al., 2011). This raises a contradiction of why multinationals are approaching the Dabbawallahs for operational and strategic advice.

The Dabbawallah operations have been six sigma certified for their simplified and flawless delivery by Forbes in 1999 (Ravichandran, 2015). Publicity surrounding the Dabbawallahs relies heavily on the Six Sigma myth, and the stories of their supposed certification abound in the media (Pathak, 2010): raising the question of why this misconception has never been clarified by researchers. The answer is simple: because it is convenient and brings into stark relief the fact that the Dabbawalas traditional systems lead to highly modern results (Pathak, 2010). Furthermore, Raju and Sowdamini (2015), quoted, "if we speak about Six Sigma in the context of the Indian industry, the first thing that comes to our mind is the Mumbai Dabbawalas. Barely, one tiffin box in 1.6 million goes astray, and in stark contrast, although airlines expect to lose about 3.09 bags for every 3,000 passengers, making it the most effective organisation in the world (Sharma, 2015).

On the contrary, Forbes never certified the Dabawallahs as a six-sigma organisation (Pathak, 2010). However, this single achievement has put the Dabbawallahs on the global map of operations management seeking interests not only from MNCs who want to learn their best practices, in several operations management journals, and textbooks (Thomke, 2012; Patel and Vedula, 2006). Thus, the longevity of the Dabbawallah food delivery service could be not sustainable on this single achievement of achieving a six-sigma certification based on Pathak (2010) contradiction. Moreover, Dabbawallahs have a strong media presence leveraging their sedentary lifestyle through cultural branding. Consequently, they are marketing their services in disguise (Pathak, 2010): suggesting there may be other forces that sustain their longevity in delivering lunches to office workers.

The initial search of the literature found business writers have focused on newspaper articles, and some academics have written in practitioner journals about the operational performance of the Dabbawallahs with inadequate connection to management theories. It raises the question of what organisations such as Amazon, Tata, and FedEx are learning from the Dabbawallah operations? The author argues that there is inadequate academic research about the operational performance of the Dabbawallahs in peer-reviewed journals. Most of the work is found in Harvard Business Review (HBR) and Sloan Management Review (SMR) which are practitioner journals. Thus, this 
research will address the gap and justifying the need for this research.

The paper starts with a brief introduction followed by a literature review, which leads to two research questions. Next, the methodology to address those research questions is presented. This is followed by reviewing the Dabbawallah operations under four key areas: operational excellence; strategic management; organisational structure and organisational culture; and marketing approach with cultural branding. The next section provides a synthesis of the findings, followed by conclusions and future research.

\section{LITERATURE REVIEW}

A broad search of papers in ABINFORM and Google scholar highlighted there are a handful of articles in HBR and SMR, and a number of academic papers produced mainly in India about the Dabbawallahs. The literature review is structured as follows: the history of the Dabbawallahs, their current operations, and its organisational culture.

Overall, practitioner journals highlighted that the Dabbawallahs has been in operations for 120 years (Thomke, 2010) when a Parsi banker employed a man from Pune to deliver his lunchbox from his home to his office (Chaudhary, 2016). The word dabbawala comes from 'Dabba', meaning box in this case lunchbox, and 'wala' refers to a man involved in a trade (Pathak, 2010). The organisation employs the lunch box deliverymen from the Vakari sect who are vegetarians are referred to as the Mumbai Dabawallah Organisation (MDO) (Pathak, 2010; Youngblood, 2003 and Thomke, 2010, 2016). This service evolved due to cultural and religious practices of Hindus who are strict vegetarians and have the preference for home-cooked food for lunch. It was the beginning of the Dabbawallah system (Chaudhary, 2016): a 'simple system' without the use of any information technology or mobile phones (Chakraborty and Hargude, 2015).

The Dabbawallahs hail from the Warkari sect (Thomke, 2012), on the contrary, other business writers and religious researchers have spelled it as the 'Varkari' sect. Thus, the term Varkari applied in the remainder of the paper. Likewise, to maintain consistency, the term Dabbawallah is used to describe the deliverymen and MDO (Mumbai Dabbawallah Organisation) in this paper.

Thomke (2016), Chaudhary (2016) and Sharma (2015) identified the following business dimensions about the operations: 5000 delivery men; monthly service cost of INR 600 - 650 rupees per customer; a turnover of INR 50 to 55 Crores per annum; 200000 daily customers; 400000 daily transactions; operating 5 days a week; 6 to 8-hour turn around cycle; ISO certified in 2000; and six sigma certification in 1998. However, researchers have merely described the operations without connecting them to any management theories or concepts.

\section{FINDINGS AND RESEARCH QUESTIONS}

In synthesizing the discussions relating to the historical, operational, organisation culture, and organisational structure of the MDO, it is apparent that there are inadequate discussions about the concepts, tools, and strategies supporting their operations and business practices. There is no record of a business model implemented in 1890 (Pathak, 2010). Given that the MDO has been delivering food to Mumbaikers for 120 years, and has not changed the way it operates indicates there could be continuous improvement initiatives taking place.

Dhondiba Medge and Gangaram Talekar, the senior managers in MDOs lacked the knowledge of management theory to translate skills and knowledge of the Dabbawallah operations into practices that could be adopted by other organisations (Pathak, 2010). Thus, it is unclear on how multinationals are sending their executives to learn about Dabbawallah management practices. Therefore, there is value in formalizing their operations with the use of operations management practices, tools, and theories that leads to the first research question (RQ1).

RQ1: What management theories, tools, techniques and strategies can be used to explain the Dabbawallah operations.

This RQ aims to reveal the tools, techniques, and theories that support MDO. Business writers and researchers have mainly discussed the success of the MDOs in terms of achieving a six-sigma certification through their operational excellence. However, there could be other factors at play (such as strategic aspects, organisation culture and strategies), which contribute to their business operations. Addressing RQ1 will provide a platform to view the MDO operations in the context of modern management practices. It is apparent there are limited discussions about which aspect of the Dabbawallahs operations leads to their success that evolves into the second research question.

RQ2: What is the most important aspect of their operations that leads to their ongoing success?

This RQ aims to reveal which aspect of the Dabbawallah operations drives the successes of its business.

\section{METHODOLOGY}

Multi-methods are used in this research: deductive reasoning; and concept mapping. Deductive reasoning is applied to explain the Dabbawallah practices and operations in terms of the existing literature on LEAN, and collaborative SC practices such as SCI. Concept mapping is based on a set of ideas and mind maps that connects two distinctive areas of Dabbawallah delivery service: their cultural and religious aspects to their operational capabilities.

In applying the deductive methodology, the Dabbawallah operations can be explained under the headings of operations management, strategic management, organisation culture, and marketing-branding. However, to address RQ2, the concept mapping is applied to develop a model to explain its success.

\section{OPERATIONS MANAGEMENT}

This section explains the approaches taken by the Dabbawallahs in the context of several operations management concepts, tools, systems, and ideologies that are applied across the SC by other organisations.

\subsection{Collaborative Supply Chain Practices}

Mahadevan (2013) defines the perceived levels of (SCI), information sharing (IS), and supply chain visibility 
(SCV) as follows - SCI is defined as the ability to connect several SC partners through technology SCI and a dominant feature in SCM (Chatzoudes and Chatzoglou, 2011); SCV is the ability to have access to the SC partners processes and data; IS refers to transactional or product-related data shared across the SC. In the context of collaborative practices, SCI, IS, and SCV leads to operational excellence (Dubey et al., 2018; Mahadevan, 2013: Popa-Anica, 2012). Mahadevan (2013) and Wieland et al. (2016) stressed the importance of SCV and internal integration within organisations, whilst Heaney (2013) discussed the connection between SCV and the organisation's profitability. Profitability and organisational productivity links to SCV and SCI (PopaAnica, 2012; Priesmeyer et al., 2012). SCV and IS improves the effectiveness and efficiency of an SC (Mahadevan, 2017). Thus, collaborative practices (SCI, SCV and IS) are the key to in the Dabbawallah operations.

In taking an operations management view, Patel and Vedula (2006), Ravichandran, (2005), Thomke (2016), and
Ganapathy (2017) describe the Dabbawallah food delivery operations as the hub and spoke operations with forward and reverse logistics connected by road and rail. Das et al.(2020) noted that is markedly different from the trend observed in forwarding logistics and is somewhat counter-intuitive. However, the author argues that Dabbawallah operations are identical in both directions. The 'Hub and Spoke' model (Fig 1) is applied for the distribution operations of the food delivery service, the logistics network, combination of the milkman route, hub to hub transfer, and hub to spoke distribution based on the work of several writers such as Patel and Vedula (2006). Furthermore, linking the coding system used with the Hub and Spoke operations, there are collaborative SC practices in the Dabbawallah operations.

Next, the approaches taken by the Dabbawallahs in the context of a number of operations management concepts, tools, and systems applied across the SC by other organisations are explained.
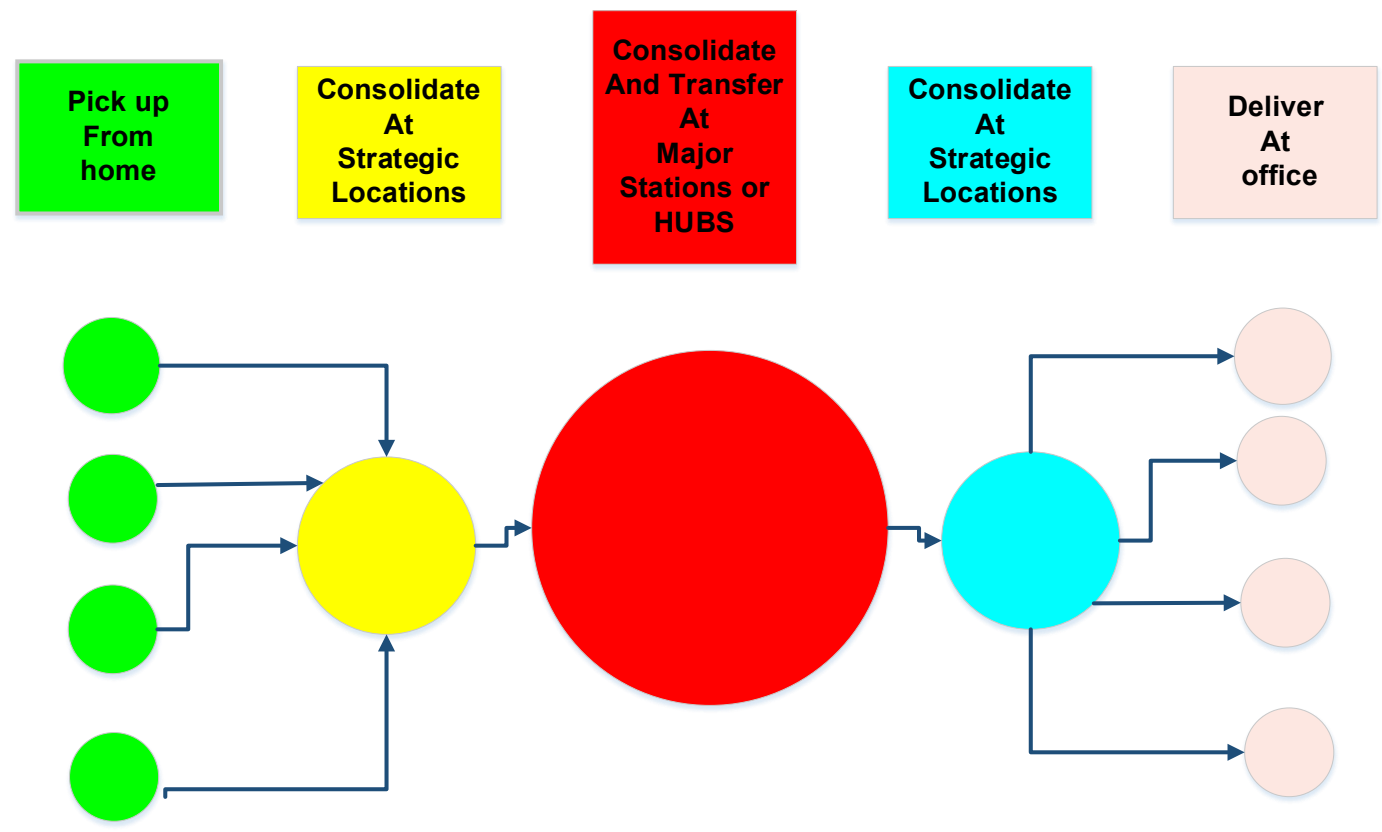

Figure 1. Hub and Spoke Operations of the Dabbawallahs

The Dabbawallahs is effectively managing an SC distributing cooked food from the home to the office through various modes of transport in an integrated SC. However, their operations are not formally explained in the context of $\mathrm{SCV}$, SCI, and IS, strategies or management tools or concepts that multinationals currently deploy.

There is a closed-loop SC with flow line process (Fig 1) based on Meredith and Schafer's (2015) work. The MDO employs a mix of transportation economics, and at the collection point, it is a milkman route structure (Ganapathy 2017) supported by a hub-to-hub transfer to handle large volumes, with reduced operational cost. At the destination point, a hub-to-spoke operation ensures efficient response time and handles volume flexibility. Therefore, there are LEAN practices in the Dabbawallah operations with different strategies.

The Dabbawallah logistics system comprises of each deliveryman collecting around 30-35 dabbas, using $25 \mathrm{~km}$ of public transport and $10 \mathrm{~km}$ of footwork involving multiple transfer points (Ganapathy, 2017). Thus, Sales and Operations Planning (SOP) technique is deployed to manage FL and RL on a daily basis using the rail network very effectively by employing simple, straight rules, mainly north-south directions, and limited sorting to a few central points (Ganapathy, 2017). It is the key to the MDO efficiency and success (Patel and Vedula, 2006; Chopra and Sharma, 2012). Thus, there are scheduling and network planning principles that are used by the MDO. In addition, the timetable of the railway system, and the standard delivery deadline for the tiffins coincides and creates a natural clock speed into the delivery operations (Ganapathy, 2017). The Dabbawallah delivery system relies on the individual workers, "a system built around train schedules, bicycles and delivery men" (Ganapathy, 2017). Thus, an integrated SC with transport information of train timetables and traffic systems providing SCV to the Dabbawallahs without the application of any SC tools in their operations.

The accurate timing and coordinated teamwork 
contribute to their success leading to teams share a common agenda (Balakrishnan and Teo, 2008). Therefore, IS component of the SC links the train schedules to the MDO that helps to synchronize everyone and imposes discipline across the food delivery SC. However, if a Dabbawallah is late dropping off his dabbas at a station, his errors or failure to meet schedule is immediately visible to the train operator or other deliverymen (Ravichandran, 2015): thus alternative arrangements are made for transporting his dabbas on another train. The deliverymen's approach to any problems in the operations needs to be resolved on the spot can be analogized to the TPS (Toyota Production System) where the employee stops the process until the fault is fixed (Meredith and Schafer, 2015). LEAN is a set of operating philosophies, that defines TPS (Vinodhini et al., 2019). Lean thinking lay out the five Lean manufacturing principles that include: value, value streams, flow, pull, and perfection (Vinodhini et al., 2019). The Value Stream is the combination of the Value Creation and Value Delivery processes (Goestch and Davies, 2016). Thus, the Dabbawallahs are creating value along the food delivery chain.

The Dabbawallah operations are unique to Mumbai enabled by the excellent train system supported by the city's linear layout. The rail infrastructure ensures flexibility and lower cost of Dabbawallah operations (Patel and Vedula, 2006) with several strategic nodes near railway stations that serve as final sorting nodes within the RL operations (Ravichandran, 2005; Balakrishnan and Teo, 2008). Therefore, there is a continuous process flow of the Dabbas from the moment it is picked up from the customers in the FL (Meredith and Schafer, 2015).
The dabbas are loaded and unloaded in the 60 seconds window when the train stops at the platform (Ravichandran, 2005). Thus, the application of the SMED (Single Minute Exchange Dies) used in manufacturing operations to reduce bottlenecks, in the 60 seconds loading time window (Joshi and Naik, 2012). Therefore, using SMED achieves LEAN for Dabbawallahs operations and lean tools overcome the waiting time problem playing a crucial part in the food delivery process (Vinodhini et al., 2019). Moreover, having achieved a LEAN status leads to six sigma certification (Meredith and Schafer, 2016). Therefore, train delays or early arrival could have the synchronicity of the uploading and the loading of the dabbas at the train stations in impacting on the LEAN operations.

The coding system (Fig 2) can be analogised to the RFID technology that contains various information about the customer pickup points and delivery points. The Dabbas can be tracked through the FL and RL operations (Usama and Ramish, 2020; Thomke, 2010, 2016). The accuracy of the coding system is partially responsible for zero defects of missing a delivery or a collection. The lunch boxes are consolidated at the floor level of the consumer location, and the customer participates in the initial and final step of the food delivery process (Ravichandran, 2015). Moreover, information on the collection route is known to every other member in the team, and so a surge in demands are well managed (Ravichandran, 2005): reinforcing IS and SCV in the delivery operations.

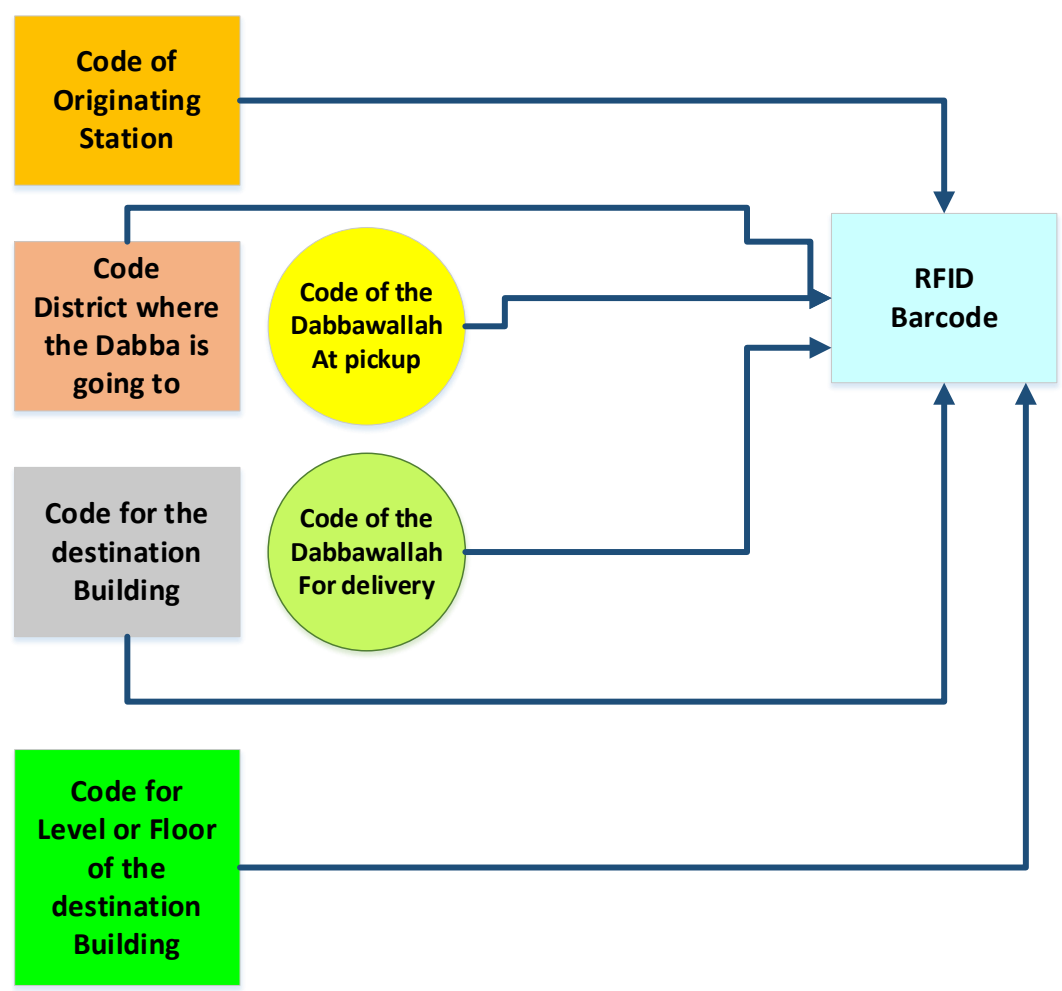

Figure 2 Coding the Dabbas 
The Dabba may change hands as many as six times in a day, however, it is this coding system that ensures seamless movement (Balakrishnan and Teo, 2008) supporting IS. The system limits the routing and sorting to a few central points with built-in constraints. However, a simple colour code determines not only packet routing but also packet prioritizing as lunch boxes travel from train to bicycle and from bicycle to foot-supporting IS (Thomke, 2010). The process gets united at the delivery end though it may appear a bit competitive at the customers' end (Chopra and Sharma, 2012): SCI takes place. The third stage is the final delivery from the strategic collection point - the cooked lunch delivered to the "receiver-customer" at about $12.30 \mathrm{pm}$ indicating there is SCV in the movement of the dabbas.

\subsection{Operational Performance}

The MDO operational performance measures are realtime where every transaction monitored in terms of its collection, transportation, and delivery, and periodic revenue collection and volume-based employee productivity ensure a model that is self-corrective (Ravichandran, 2005). On the other hand, there are limited discussions about the quality tools, the MDO use to collect data and measure the transactional processes. Thus, there is inconclusive evidence if the MDO is measuring processes leading to the six-sigma certification periodically. Fan et al. (2017) developed the "engineering restaurant manager" that provides the Ubereats analytics dashboard on customer satisfaction, service quality, and sales using real-time information linking the restaurant to the customer, and measure delivery times: the MDOs could adopt this technology to measure their performance.

\section{DABBAWALLAH ORGANISATIONAL CULTURE AND STRUCTURE}

Each organisation has a unique organisational culture (Peters and Waterman, 1982), and has a structure for finance, human resources, marketing, and operations functions (Griffin, 2015). Moreover, a company's culture and willingness to learn and absorb knowledge from its customers, suppliers, or internally, all impacting firm performance (Khan and Wisner, 2019). American management has its roots in productivity, whilst Japanese management in quality and Indian management has its basis in self-management (Purohit and Sharma, 2017). Indian ideas have received global attention, reflected in the popularity of yoga, meditation, and Indian spirituality (Purohit and Sharma, 2017). Thus, the notion of selfmanagement could be well entrenched in the MDO ethos driven by the Varkari principles, intertwined with organisational culture.

The most prominent yardstick of the quality in the world is Six Sigma and the credit goes to Japan as a contributor from its oriental practices, "Martial Arts", and Buddhism (Rath et al., 2011). However, Japan learned these concepts and techniques from India through Buddhism and Buddhist monks (Rath et al., 2011). Thus, six sigma originated from India that has become very tightly linked to the organisational culture. Mahadevan's (2017) research on culture-driven regeneration (CDR) identified similar mindsets in an organisation can contribute to a "weak culture". The CDR tool also links the knowledge level of an organisation with the number of different mindsets and years of service in the organisation (Mahadevan, 2017). This weak culture leads to flexibility in the Dabbawallah operations, whilst an "active knowledge" repository exists at the operational level as deliverymen have similar mindsets delivering lunch in Mumbai for many years. Thus, driven by the Varkari mindset, it is evident that organisational culture plays a vital role in the Dabbawallah operations.

The Dabbawallah operations have an organisation structure where deliverymen report to the supervisors, and there is no direct line supervision, but there is an administration function by the Mukadams (Roncaglia, 2013). The Dabbawallahs based their operations have an overall system whose basic pillars comprises of organisation, management, process, and culture (Thomke, 2016, 2012: Pathak 2010; and Ravichandran, 2015). Moreover, each of the pillars contributes to a system that focuses on achieving one goal: on-time delivery (OTD) (Thomke, 2012). Thus, the OTD is indirectly connected to SCI and IS in the delivery process with a flat structure with local autonomy which is suited in providing a low-cost delivery service. SCI also increases flexibility (Porter, 2019).

Although there is no discussion about formal leadership style, the Dabbawallahs have a strict code of conduct with a hidden autocratic leadership in place as managing a virtual organisation of 5000 deliverymen in time-critical operations requires discipline (Pathak, 2010). Moreover, their organisational culture is infused with Dabbawallah culture plays a big part in their operations (Pathak, 2010). Thus, organisational culture and leadership are intertwined (Mahadevan, 2017).

\section{STRATEGIC MANAGEMENT}

MDO has an excellent business model based on an innovative approach (Ganapathy et al., 2016), and its mission statement is, to always delight the customer, which can be analogized to delivering food to office workers is like a service to God (Thomke, 2016). However, the MDO must have a number of operational and business strategies to manage their food delivery operations, although the literature does not explicitly mention this.

The MDO charge INR 650 per month for the food delivery services deploying lowest cost strategy (Gamble et al., 2016). They also deploy a diversified product strategy in delivering KFC chicken wings, milk, and vegetables, and home-cooked non-vegetarian meals (Dutt, 2016). MDO has recently taken into account the changes in the Mumbai workforce demographics and they deliver food cooked by the wives of the deliverymen to working couples to the office (Dutt, 2016). Thus, the business is sustainable and expected to grow.

The Hub and Spoke model has different operational aspects at the customer pick up the end and at the delivery end (Fig 1). At the customer pickup point, the demand could vary (Patel and Vedula, 2006), thus the chase strategy for demand management could be applied in this part of the SC. However, the return process will have a constant demand, thus the levelling strategy is applied. From the operational strategy perspective, the Dabbawallahs are using continuous flow or repetitive flow. UberEats applies a continuous flow 
strategy and could perform the Dabbawallah operations by integrating train timetables, Apps, and traffic flow patterns using motorcycles. Samuel et al. (2020) predict a growth of USD100 billion for online food delivery Apps in India with Kapoor and Vij (2018) envisaging its phenomenal growth in major cities (Selvan and Susan, 2019). However, from a cost perspective, it is not known if UberEats can provide a competitive rate of INR 650 per customer taking into account the costs of operating communication systems encompassing networks, phones, and motorcycle transportation.

The Dabbawallahs mainly use word of mouth as a marketing strategy (Pathak, 2010), although www.mydabbawala.com is used to advertise their services (Patel and Vedula, 2006). The Website and mobile phones have helped the MDOs to connect to the outside world and fetch more customers and advertisers (Sethi et al. 2014). In recent times the viral marketing using social media marketing has had a significant impact on the Dabbawallah food services (Chopra, 2017). In terms of finance strategies, there are inadequate discussions about MDO investing their earnings from a turnover of INR 50 to 55 Crores per annum.

There is no formal human resources strategy applied by the MDO and the selection process is a closed shop. Given the Dabbawallahs are nearly illiterate, the Mukadam participates in the recruitment processes, and the selection is based on their reputation and shared origins with other members of the organisation (Ganapathy, 2017). Thus, religious and cultural beliefs are more important that their operational skills set. Moreover, Dabbawallahs earn by Indian standards, a decent wage of some INR12,000 or USD 200.00 per month for the menial work (Pilling and Chikoti, 2015).

Overall, from a strategic business model perspective, the MDO could be explained using some of the conventional strategies. However, marketing, human resources, and financial strategies are not explicitly discussed by business writers (Gamble and Peteraf, 2010). These simple food deliverymen have achieved so many feats without a formal education, guided by their instincts, inherent skills and competency (Pathak, 2010). However, the MDO model defies all conventional logic and is therefore counterintuitive and has no unique scientific and or technological breakthroughs (Ganapathy et al., 2016). By using Porter's Five Forces, and PEST, the current strategic position of MDOs against other similar organisations can be established. However, there is insufficient information to proceed with such an analysis.

\section{MARKETING THROUGH CULTURAL BRANDING}

In recent times "branding" has become a key component in making a person, product, or service more visible and marketable. Since their write up by Forbes about six sigma, the MDO has become "fixtures" in the Indian public culture. Organisations like Coca-Cola, HarleyDavidson, Nike, and Budweiser are cultural icons valued by customers more for what they symbolize than for what they do (Holt, 2003).

Corporate films have emerged as a key tool for corporate marketing (Schroeder, 2017). Several high-profile brands have hired well-known film directors to produce films for their corporate marketing (Bell et al., 2014; Meyer et al., 2013): Martin Scorsese for Dolce and Gabbana; Wes Anderson for Prada; and Ridley Scott for BMW. A related strategic initiative involves "the making of" branding and advertising campaigns, in which brands hire a second camera crew to make a short video about a high-profile brand campaign or corporate marketing shoot.

In his book, "How Brands Become Icons: The Principles of Cultural Branding", Holt (2003) explains the theory of cultural branding and brands that achieve iconic status in popular culture are the ones that create value at a cultural level. Moreover, the brand comes to represent an idea or a value, and the brand's impact depends upon its ability to tap into channel deep-seated desires into consumer activity. Thus, an iconic brand not only represents a product or organisation but a way of life (Holt 2003).

In the case of achieving cultural branding, Ragunath Medge and Gangaram Talekar, the centre of power within the Dabbawallahs universe leverage their charismatic leadership to gain branding for their operations (Pathak, 2010). These leaders are the public face of the Dabbawallahs and are regarded as the architect of their media visibility, although lack in management theory to translate their skills and knowledge into practices that other organisations could adopt. In addition, they recognise the cultural value of the Dabbawallah brand as a source of power and is actively engaged in branding tactics to maintain its iconic status (Pathak, 2010). The duo offered an entertaining presentation that held the promise that ordinary Indians could achieve results considered extraordinary by modern standards (Pathak, 2010) and they used the forum to propagate their cultural brand value by positioning MDO as a socially driven organisation. Moreover, abstract concepts such as 'Indian tradition', 'cultural authenticity', 'dedication', 'simplicity', and 'efficiency', are demonstrated in the Dabbawallahs' role. These concepts become to be associated with it in a way that makes the Dabbawallahs brand equity, or brand perception. Moreover, Dabbawallahs are more into the "branding strategy" rather than the logistics of their operations (Pathak, 2010). Thus, demand for the food delivery service is selfperpetuating by their cultural branding.

\section{THEORETICAL PERSPECTIVES}

In the context of theoretical perspectives, the Network Theory (NT) can be used to explain the Dabbawallah's Hub and spoke operations (Ganapathy, 2017). The Theory of Constraints (TOC) is based on the weakest link in the supply chain (Simsita et al., 2014). In the case of MDO, the weakest link is the rail system, where delays can impact the movement of the dabbas in FL and RL. However, Mahadevan (2013) has used theories such as RBV (Resource Based View) (Halldorsson et al., 2007); and NT (Network theory) (Halldorsson et al., 2007) to interpret FL and RL in the context of SC collaborative practices. On the contrary Brun et al. (2020) uses relational theory to explain the relationship between the SC partners that can be mirrored in the Dabballawah operations to explain the links between the different transport systems.

In FL and RL, the resource-dependent theory (RDT) and RBV imply that collaboration between members of the SC can bring about better results (Moubed and Mehrjedi, 2014; Mai et al., 2012). RBV suggests that effective use of a firm's unique resources can lead to sustained competitive 
advantage. Thus, TCE and RBV can be used to explain the theoretical aspects of RL of the dabbas (Lau and Wang, 2009). Dubey et al. (2018) found that RBV is used to study the relationship between IS and SC connectivity to SCV and performance in terms of $\mathrm{SC}$ resilience and robustness. Therefore, TOC, TCE, and RBV are best positioned to provide the theoretical explanations of the Dabbawallah operations.

\section{SYNTHESIS OF THE KEY AREAS OF DISCUSSIONS}

In synthesizing the theoretical perspectives, cultural branding, organisation structure and culture, strategic management, and operations management, the author concludes that there are conceptual explanations for the Dabbawallah operations that can be related to the operational and cultural practices of multinational corporations.

The connection between the FL and RL sequence (Table 1) includes activities, strategies, tools, techniques, systems, culture, and knowledge. There is a collaboration between the rail system, road, and the Dabbawallah's mode of transport; therefore the integration of different forms of transport leveraging IS where the train timetable provides SCV of the journey with approximate times of delivery. Further, the coding of the Dabbas can be analogized to the RFID concept without the technology which enables IS between food deliverymen at different points along the food delivery chain. The Dabbawallahs are managing food delivery operations in a 6 to 8 hours turnaround meeting six sigma criteria without the formal application of strategies.

The concept of working around the train timetables, carts, and bicycles is regarded as the SCI of the multi-mode transport systems. Whilst their food delivery may be stated as a simple process, however, it is evident that they unknowingly apply LEAN (SMED) strategy (Gunasekaran et al., 2001) in loading and unloading dabbas from the train in the 1-minute window. The author argues that the Dabbawallahs could be also applying JIT (Just in Time) which is gaining recognition across a wide range of industries (Son, 2019). Thus, a link between train systems, "Dabba codes" and the transport systems, and the collaborative SC practices can be established.

For LEAN to thrive in an organisation, it must be supported by its culture (Bhasin, 2013). In applying Mahadevan's (2017) CDR concept, the Dabbawallahs have a "weak culture" and an "active knowledge" (Table 1) based on the identical mindsets of the deliverymen (Thomke, 2012). Thus, the author connects the "weak culture" of the Dabbawallahs to its LEAN operations leveraging Bhasin's (2013) work.

The connection between organisation culture, SMED, and collaborative SC practices, which leads to LEAN, is presented in Fig 3.

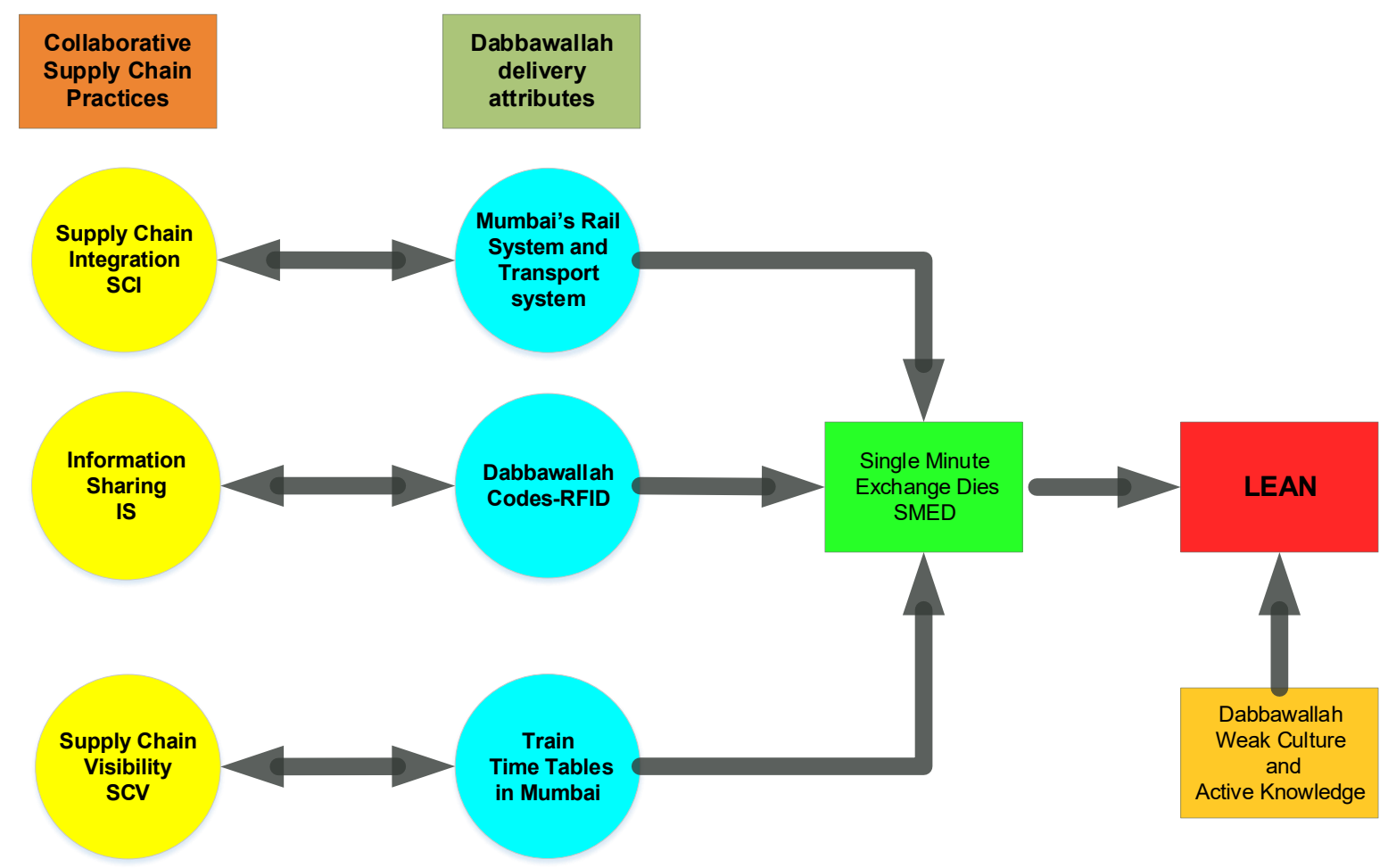

Figure 3 Linking organisation culture to collaborative SC practices leading to LEAN 


\begin{tabular}{|c|c|c|c|c|c|c|c|c|}
\hline \multirow{6}{*}{ 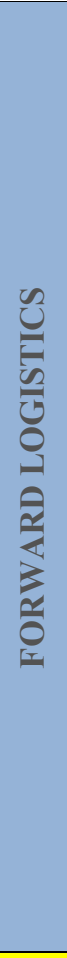 } & - & 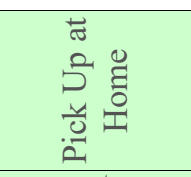 & 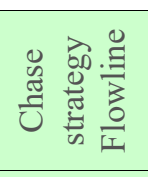 & 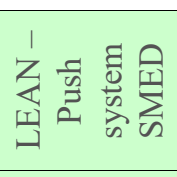 & 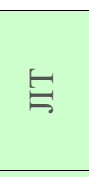 & 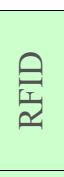 & 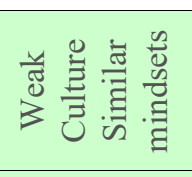 & 忌 \\
\hline & $\sim$ & $\begin{array}{l}0 \\
.0 \\
0 \\
0 \\
0 \\
0\end{array}$ & 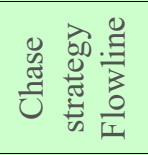 & 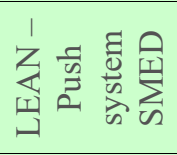 & $\stackrel{બ}{g}$ & 空 & 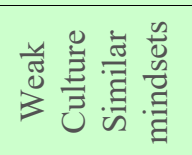 & 冚 \\
\hline & $m$ & 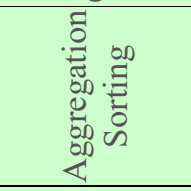 & 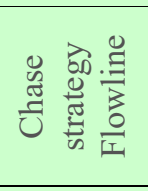 & 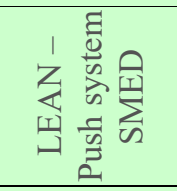 & 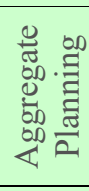 & $\underset{\underline{1}}{\theta}$ & 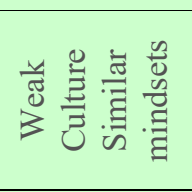 & 冚 \\
\hline & $\nabla$ & 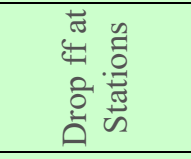 & 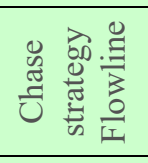 & 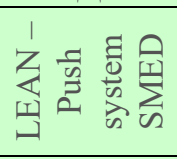 & $\stackrel{\ominus}{g}$ & 墒 & 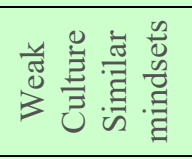 & : \\
\hline & in & $\begin{array}{l}5 \\
\substack{0 \\
0} \\
0\end{array}$ & 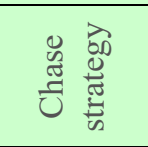 & 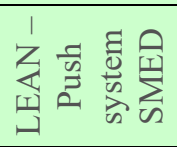 & 可 & 㚇 & 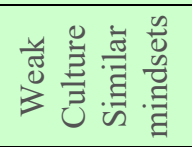 & 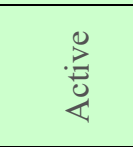 \\
\hline & 0 & 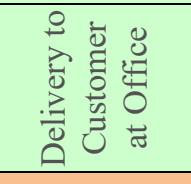 & 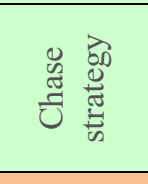 & 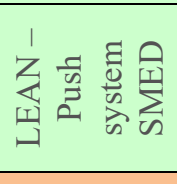 & 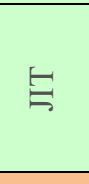 & $\underset{\underline{I}}{\stackrel{\theta}{x}}$ & 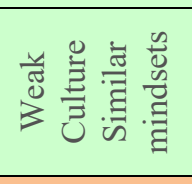 & : \\
\hline \multirow{7}{*}{ 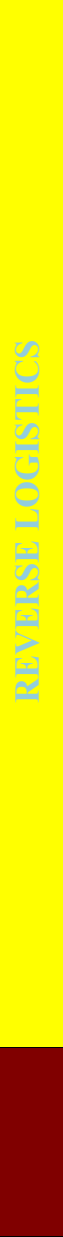 } & 0 & 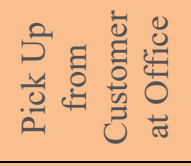 & 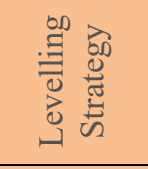 & 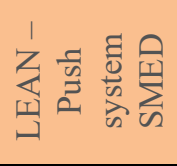 & $\stackrel{બ}{\ominus}$ & 产 & 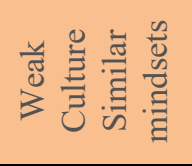 & 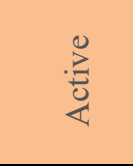 \\
\hline & $n$ & 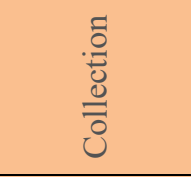 & 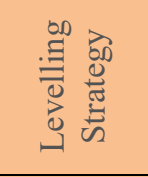 & 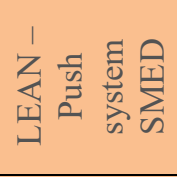 & 旨 & $\underset{1}{9}$ & 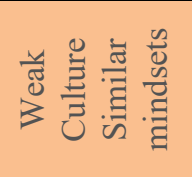 & 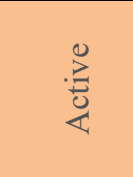 \\
\hline & $\nabla$ & 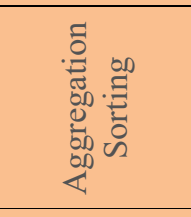 & 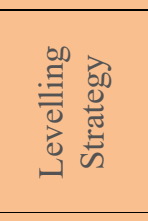 & 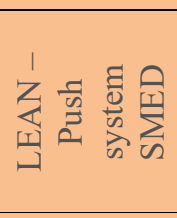 & 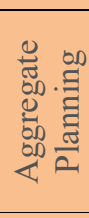 & 空 & 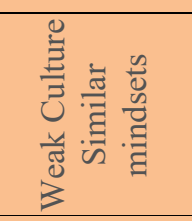 & : \\
\hline & $m$ & 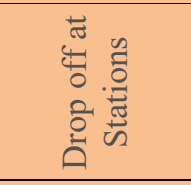 & & 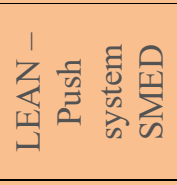 & 兒 & 㚇 & 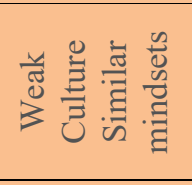 & : \\
\hline & $N$ & $\frac{\text { aे }}{\frac{0}{0}}$ & $\begin{array}{l}\stackrel{\infty}{\Xi} \\
\stackrel{\Xi}{0} \\
0 \\
. \\
.\end{array}$ & 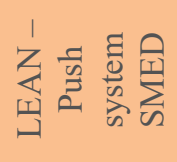 & $\stackrel{\leftrightarrows}{\triangleq}$ & 屋 & 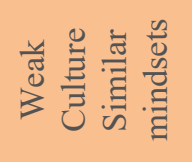 & 总 \\
\hline & - & 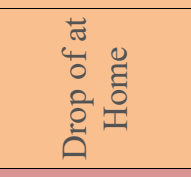 & 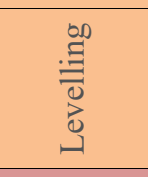 & 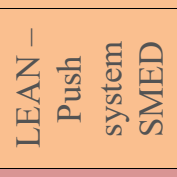 & $\triangleq$ & 㚇 & 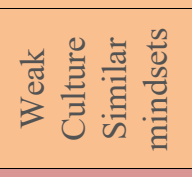 & : \\
\hline & 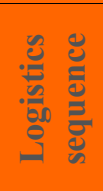 & 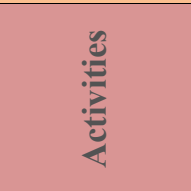 & 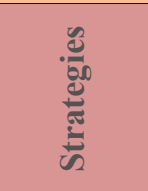 & $\frac{n}{8}$ & 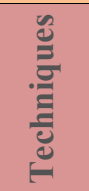 & 气ू & 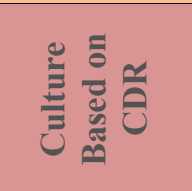 & 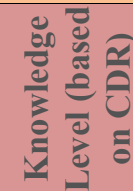 \\
\hline
\end{tabular}




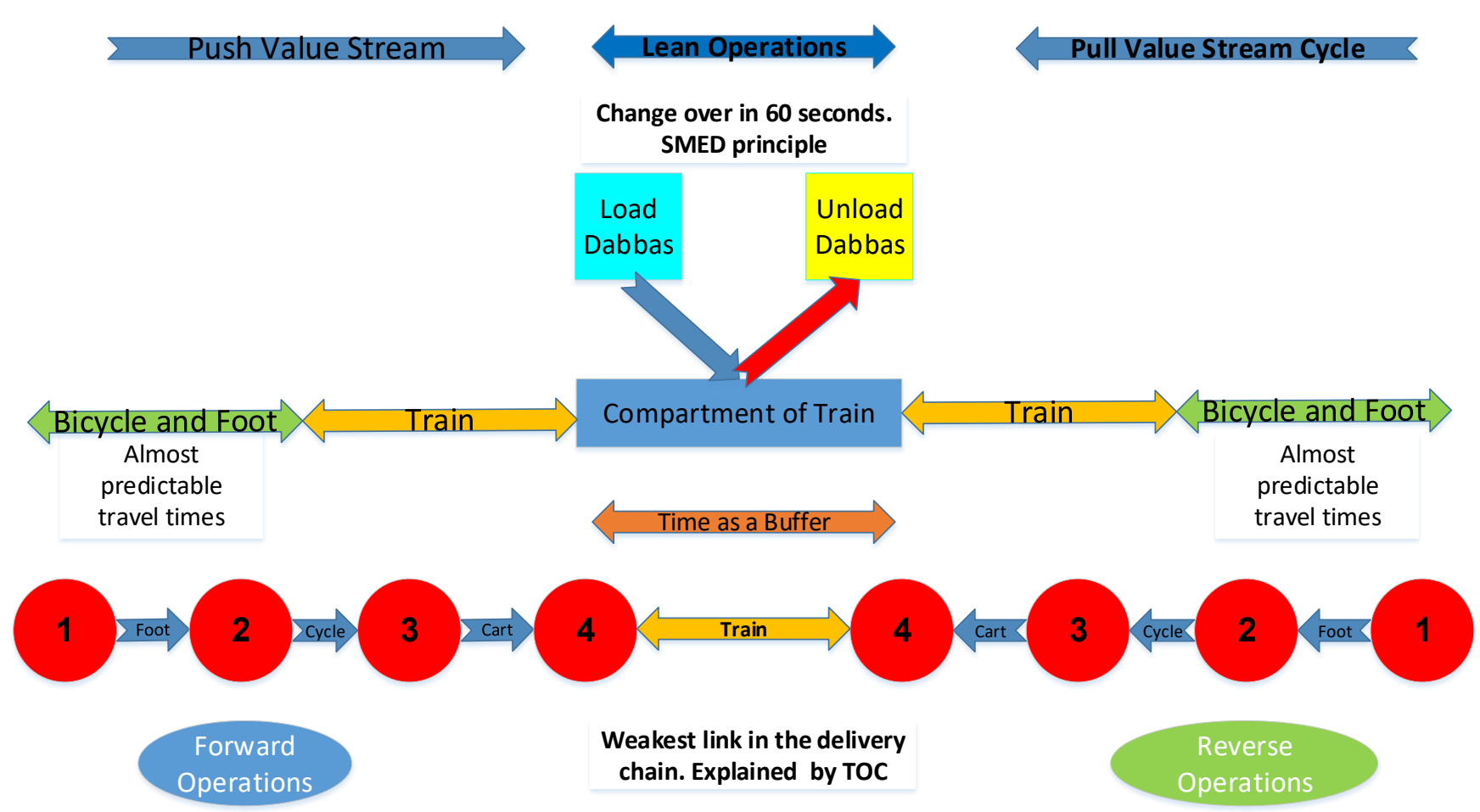

\section{Length of the journey (Train, Cycle, Cart and Foot) $=45 \mathrm{~km}$ each way}

Figure 4. Schematic representation of LEAN operations with TOC

A schematic representation (Fig 4) of the operations showing the connection with (Simsita et al., 2014), LEAN and SMED in loading and unloading of the dabbas. Based on the principles of TOC, the weakest link is the arrival and departure of the trains. Furthermore, the time spent on the road, bicycle, and foot in the delivery processes are usually predictable.

The publicity gained through movies (such as the Lunchbox) and the media hype of the Dabbawallahs are the iconic cultures that are keeping them popular in the eyes of the Mumbaikers and with the charismatic leadership of Medge who uses "simplicity", Indian culture and "Indianisation" to project the organisation. Subsequently, the general public shows respect and gives way to Dabbawallahs wearing white uniforms and caps on the trains as they are seen as performing a service and not a business activity allowing them to operate without difficulty. The Spartan lifestyle, the organisation culture, and the strict moral code of the MDOs have trained them to be self-reliant and disciplined. Thus, the author confirms that based on these discussions, the Dabbawallahs operations can be explained with modern management practices and organisational culture which addresses the requirements of RQ1.

Next, the author will identify which of those practices has the biggest impact on the deliverymen's operations. In revisiting, the Dabbawallah operations under the headings of operations management, strategic management, organisation culture, and marketing as previously discussed, the author developed a model and the four headings can be referred to as the "four forces" (Fig 5). Amit and Zott (2001, p.511) articulate that business models can be conceptualized as the content, structure, and governance of transactions designed to create value. Business models can also serve as important strategic tools in innovation and market formation processes (Wieland et al., 2017).

The rationale behind this model is that the forces drive each other analogizing the PDCA cycle - (the 4 individual boxes: cultural branding Box 1; organisation culture and structure Box 2; strategic management Box 3; and operational management Box 4) with an arrow in the clockwise direction. The four forces are equally important in this model and rotate in a clockwise direction depicted by the arrow in the centre. The link between the four forces is the LEAN operations supported by TOC which are accepted by both academics and practitioners (Goldratt, 2009). Conversely, LEAN is a consolidated approach in Operations Management since the first studies of Ohno and Shingo (Des Jesus Paechecco et al., 2018). Des Jesus Paechecco et al.(2018) also established a link between TOC and LEAN in the manufacturing space spanning a multitude of Operations Management sub-disciplines. In addition, Scheinkopf and Moore (1998) pointed out the similarity of the connection between the TOC and Lean are the perception of value from the customer's perspective, value stream, the flow, and the production are pulled, they offer techniques to control the flow using the concept of pulling the market demand, search for continuous improvement. Thus, the author has connected SMED, LEAN, and TOC to demonstrate the push value stream in the FL and the pull value stream in the RL of the Dabba movements. By leveraging a LEAN tool, PDCA (Plan, Do, Check, Act), an iterative, four-stage approach for continually improving processes, products or services, and for resolving problems (Goestch and Davies, 2016), the Dabbawallah Model is conceptualized (Fig 5). 


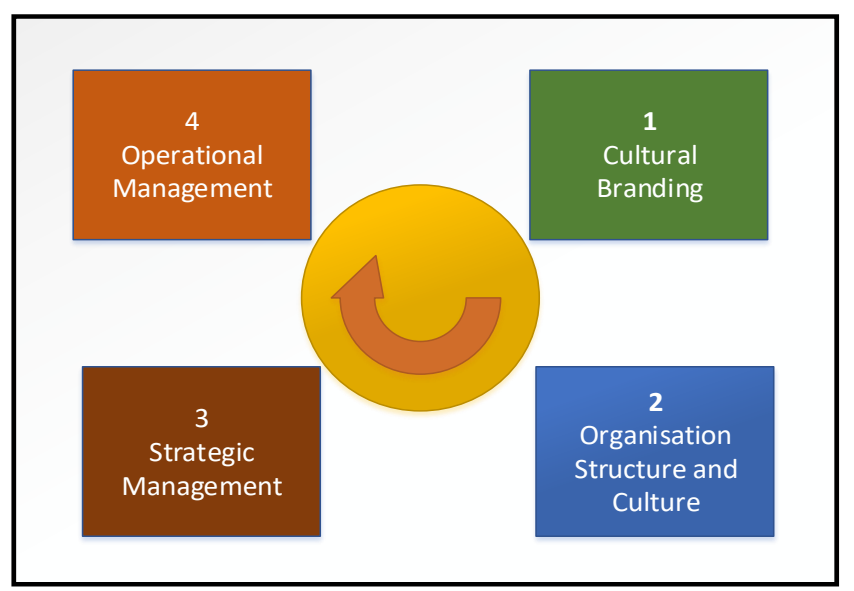

Figure 5. The Dabbawallah Four Forces Model

The author argues that the cultural branding (box number 1) is the major force as the Dabbawallahs are very high profile in Mumbai for their simple lifestyle with significant media hype. Pathak (2010), Pilling and Chilkoti (2015), and Ganapathy et al.(2016) found that the Dabbawallah leaders utilize their public presentations have created a "brand" for the simple delivery service (minimal resources or LEAN) with six sigma status, that perpetually creates a demand for their services. The simple "Spartan" like culture based on the Varkari beliefs, and connects to Box number 2 (organisation structure or culture), which in turn drives its LEAN operations structure supported by the information shared across the food delivery chain through the codes used on the dabbas.

The "weak culture" and "active knowledge" leading to LEAN operations connect to the strategies (Box number 3). The LEAN operations drive the choice of the strategies (Just in Time, LEAN, chase, or levelling), whilst the application of the strategies such as chase strategy is based on the demand fluctuations.

Finally, the chosen strategies enable the forward and reverse operations in the efficient delivery service (Box 4) meeting operational excellence supported by TOC and potentially leading to six-sigma certification. This in turn adds to the credibility to the Dabbawallah leaders who continue to tell the public about their success supporting the cultural branding and continuing the cycle.

Thus, by addressing RQ1 and 2, the Dabbawallah operations are demystified and give the reader a holistic view of this successful world-renowned business in the context of management and cultural practices. It also reveals that although Dabbawallah success is orchestrated in terms of its LEAN operations by business writers and researchers, it is the cultural branding that keeps it going.

\section{CONCLUSION}

This research has provided academics, practitioners, and researchers a holistic view of the Dabbawallah operations explained with operations management principles and theory. The Dabbawallahs effectiveness and efficiencies are powered by their cultural branding made up of their media exposure, movies, press releases by the Dabbawallah leaders, and the public perception of their Spartan-like lifestyle. The cultural branding is keeping the need for their foodservice operations going by perpetually creating demand, and further drives the organisation culture, which in turn sets the strategic plan. Thus, the strengths of cultural branding flow through the operations, strategies, and processes, leading to achieving six-sigma status.

In explaining their trade secrets to the multinationals, the Dabbawallahs are merely selling the "simplicity" of their operations to managers attending their presentations: the deliverymen are like trained military personnel working in a synchronized fashion who are effective and efficient with minimal resources. Therefore, the Dabbawallahs are teaching multinationals LEAN operations management based on religious and cultural practices. On the other hand, performing this simple service to the community with a profit, the Dabbawallahs believe they are reducing their Karma: something the multinationals are not ready to fathom.

Future researchers could extend this research by benchmarking different food delivery service by measuring with UBEReats and Menulog. Uvet's (2020) work on the critical elements of the quality of service could be incorporated in the benchmarking exercise. Mathematical modelling could be incorporated into the studies to set industry benchmarks.

\section{REFERENCES}

Amit, R., \& Zott, C. (2001). Value creation in e-business. Strategic Management Journal, 22(1), pp. 493-520.

Balakrishnan N., \& Teo CP. (2008) Mumbai Tiffin (Dabba) Express. In: Tang C.S., Teo CP., Wei KK. (eds) Supply Chain Analysis. International Series In Operations Research \& Management, vol 119. Springer, Boston, MA.

Bell, E., Warren, S., \& Schroeder, J. (2014). The visual organization (E. Bell, Warren, S., and Schroeder, J. (Eds), Ed.). Routledge.

Bhasin, S. (2013). Impact of corporate culture on the adoption of the Lean principles. International Journal of Lean Six Sigma, 4(2), pp.118-140.

Brun, A., Karaosman, H., \& Barresi, T. (2020). Supply Chain Collaboration for Transparency Sustainability 12, (11), pp 1-21.

Chakraborty, A., \& Hargude, A. N. (2015). Introducing Technology to the Dabbawalas of Mumbai In Proceedings of the 17th International Conference on Human-Computer Interaction with Mobile Devices and Services Adjunct

Chatzoudes, D., \& Chatzoglou, P. (2011). The Impact of 360 
degree Supply Chain Integration on Operational and Business Performance. Operations and Supply Chain Management, 4(2/3), pp. 145 - 156

Chaudhary, S. (2016). All You Need to Know About Mumbai's Amazing Dabbawalas. Theculturetrip.com. Retrieved $22 \quad$ April 2016 from http://theculturetrip.com/asia/india/articles/all-youneed-to-know-about-mumbais-amazing-dabbawalas/

Chauhan, A. (2016). Mumbai Dabbawallahs to start their own company. Times of India. http://timesofindia.indiatimes.com/city/ahmedabad/M umbai-dabbawalas-to-start-owncompany/articleshow $/ 50621880 . \mathrm{cms}$

Chopra, M. (2017). Viral Marketing: Impact on business organisations Inspira - Journal of Modern Management \& Entrepreneurship, 7(October), pp.71-78.

Chopra, R., \& Sharma, H. (2012). Corporate to Cooperative Entrepreneurial Leadership in Emerging EconomyLessons from Indian Enterprises. Journal of Organisation and Human Behaviour, 1(4), 12-28.

Das, D., Kumar, R., \& Rajak, M. K. (2020). Designing a Reverse Logistics Network for an E-Commerce Firm: A Case Study. Operations and Supply Chain Management, 13(1), pp. 48 - 63

Dubey, R., Atlay, N., Gunasekaran, A., Blome, C., Papadopoulos, T., \& Childe, S. J. (2018). Supply chain agility, adaptability and alignment: Empirical evidence from the Indian auto components industry. International Journal of Operations \& Production Management, 38(1), pp. 129-148.

Dutt, A. (2016). Mumbai Dabbawalas won't just carry meals, will cook them for you too. Hindustan Times. http:/www.hindustantimes.com/mumbai/mumbaidabbawalas-won-t-just-carry-meals-will-cook-themfor-you-too/story-hNobrovfCxiLsWLsXQLmRL.html

Fan, J., Fu, X., Abbassi, F., \& Chao, J. (2017). Engineering Restaurant Manager, our UberEATS Analytics Dashboard. https://eng.uber.com/restaurant-manager/

Gamble, J. E., \& Thomson, J. A. A. (2015). Essentials of strategic management: the quest for competitive advantage McGraw-Hill Irwin.

Ganapathy, V. (2017). Mumbai Dabbawalas. Social entrepreneurs who make India proud. GRIN Verlag.

Ganapathy, V., Mahadevan, P., \& Ravikeerth, J. V. (2016). An Empirical Study of the feasibility of introducing the Mumbai Dabbawala Food Delivery System in Bangalore. SIBM Pune Research Journal, XII (9-22 December).

Goetsch, D. L., \& S. Davis, S. (2016). Quality Management for Organizational Excellence: Introduction to Total Quality. (8th ed.). Pearson.

Goldratt, E. M. (2009). Standing on the shoulders of giants production concepts versus production applications: the Hitachi tool engineering example Gestão and Produção, 16(3), pp. 333-343.

Griffin, R. W. (2015). Fundamentals of Management Cengage.

Gunasekaran, A. (2001). Performance measures and metrics in a supply chain environment. International Journal of Operations \& Production Management, 21(1/2), pp. 71-87.

Gunasekaran, A., Patel, C., \& McGaughey, R. E. (2004). A framework for supply chain performance measurement. International Journal of Production Economics, 87(3), pp. 333-347.

Gupta, A., Singh, R. K., \& Suri, P. K. (2017). Analysis of Challenges faced by Indian Logistics Service Providers. Global Advanced Research Journal of Management and Business Studies 6 (5), 111-120.

Halldorsson, A., Kotzab, H., Mikkola, J. H., \& SkjøttLarsen, T. (2007). Complementary theories to supply chain management. Supply Chain Management 12(4), pp. 284-296. https://doi.org/10.1108/13598540710759808

Heaney, R. (2013). Supply chain visibility: Critical Strategy to optimise cost and service. Aberdeengroup.

Holt, D. (2003). How Brands Become Icons: The Principles of Cultural Branding Harvard Business School Press.

Joshi, R., \& Naik, G. R. (2012). Application of SMED Methodology- A Case Study in Small Scale Industry, International Journal of Scientific and Research Publications, 2(8) August, pp. 1-4.

Khan, H., \& Wisner, J. D. (2019). Supply Chain Integration, Learning, and Agility: Effects on Performance. Journal of Operations and Supply Chain Management, 12(1), pp.14-23.

Kritchanchai, D. (2012). A Framework for Healthcare Supply Chain Improvement in Thailand. Operations and Supply Chain Management: An International Journal, 5(2), pp.103-113.

Lau, K. H., \& Wang, Y. (2009). Reverse logistics in the electronic industry of China: a case study, Supply Chain Management: An International Journal 14(6), pp. 447465.

Mahadevan, K. (2013). Investigation of collaborative supply chain practices through integration, visibility and information sharing: theoretical and industry perspective Western Sydney University]. Sydney.

Mahadevan, K. (2017). Measuring collaborative effectiveness: a conceptual approach. International Journal of Productivity and Performance Management, 66(8), 1105-1127.

Mahadevan, K. (2017) Culture driven regeneration (CDR): A conceptual business improvement. TQM Journal, 29 (2), pp. 403-429.

Mai, E., Chen, H., \& Anselmi, K. (2012). The role of returns management orientation, internal collaboration, and information support in reverse logistics. Journal of Transportation Management, 23(1), pp. 45-59.

Mangla, S. K., Kusi-Sarpong, S., Luthra, S., Bai, C., Jakhar, S., Kumar, K., \& Khanf, S. A. (2020). Operational excellence for improving sustainable supply chain performance. Resources, Conservation and Recycling, 162, (Nov).

Meredith, J. R., \& Shafer, S. M. (2016). Operations Management for MBAs (7th ed.). Wiley.

Meyer, R. E., Hšllerer, M. A., Janscary, D., \& van Leeuwen, T. (2013). The visual dimension of organizing, organization, and organization research. Academy of Management Annals, 7(1), pp. 487-553.

Patel, N., \& Vedula, N. (2006). Dabbawalas of Mumbai [White Paper]. Kenan-Flagler Business School.

Pathak, G. S. (2010). Delivering the Nation: The Dabbawalas of Mumbai. South Asia: Journal of South 
Asian Studies, 33(2), pp. 235-257.

Peters, T. J., \& Waterman, R. H. J. (1982). In search of excellence: lessons from America's best run companies. Harper \& Row

Pilling, D., \& Chilkoti, A. J. (2015 July 31). Dabbawalas: Mumbai's lunchbox carriers. Financial times

Popa-Anica, I. (2012). Food traceability systems and information sharing in food supply chain. Management \& Marketing Challenges for Knowledge Society, 7(4), pp. 749-758.

Porter. M.G. (2019). Supply Chain Integration: Does Organizational Culture Matter? Operations and Supply Chain Management: An International Journal, 12(1), pp. 49-59.

Priesmeyer, R. H., Seigfried, R. J., \& Murray, M. A. (2012). The whole supply chain as a wholistic system: a case study. Marketing \& Management: Challenges for the Knowledge Society 7(4), pp. 554-564.

Purohit, P., \& Sharma, S. (2017). Paradigm Shift in Management: An exploratory study on Indian Management. Bloomsbury Publishing

Rath, J., Swagerman, A., Krieger, H., Ludwinek, A., \& Pidury, L. (2011). Promoting ethnic Entrepreneurship in European cities. Publications office of the European Union, Luxembourg.

Ravichandran, N. (2005). World Class Logistics Operations: The Case of Bombay Dabbawallahs.

Roncaglia, S. (2013). Feeding the City: Work and Food Culture of the Mumbai Dabbawalas. Open Book

Scheinkopf, L., \& Moore, R. (1998). Theory of Constraints and Lean Manufacturing; Friend or Foes? Chesapeake Consulting Inc.

Schroeder, J. E. (2017). Corporate branding in perspective: a typology. European Journal of Marketing, 51(9/10), pp. 1522-1529.

Selvan, S. A., \& Susan, A. (2019). Emerging Trends Towards Online Food Delivery Apps in India 4th Annual Research Conference At: Trincomalee Campus, Eastern University, Sri Lanka,

Sethi, M., Guha, S., \& Agarwal, A. (2014). Innovative Marketing Channels in India: Utilizing the Brand Image of Mumbai Dabbawala and Indian Premier League. Asian Journal of Management 5 (2), pp. 162165.

Sharma, K. (2015). The most efficient organization in the world: The Dabbawalas of Mumbai. https://www.linkedin.com/pulse/most-efficientorganization-world-dabbawalas-mumbai-kaustubhsharma.
Şimşita, Z. T., Günayb, N. S., \& Vayvayc, O. (2014). Theory of Constraints: A Literature Review Procedia - Social and Behavioral Sciences. International Strategic Management Conference., 1(50) (September ), pp.930936

Son, J. Y. (2019). Fixed Shipping Cost Allocation for Justin-Time (JIT) Lot-Splitting. Operations and Supply Chain Management, 12(4), pp. 212-224.

Talekar, G., \& Medge, R. (2005, Jan 8th to 11th). Six Sigma in Practice: Bombay Dabbawallah Operations. 37th Annual Convention of Operational Research Society of India, Ahmedabad, India

Thomke, S. (2012). Mumbai's Models of Service Excellence. Harvard Business Review November. https://hbr.org/2012/11/mumbais-models-of-serviceexcellence

Thomke, S. H. (2012). What CEOs can learn from the Dabbawallahs of Mumbai. Harvard Business Review November, Mumbai's Models of Service Excellence (November). http://www.afr.com/business/what-ceoscan-learn-from-the-dabbawalas-of-mumbai20121203-jyydw\#ixzz4CSCXcQfN

Thomke, S. H., \& Sinha, M. (2010). The Dabbawala System: On-Time Delivery, Every Time. Harvard Business School Case Feb 2010 (Revised January 2013), pp. 610-659.

Usama, M., \& Ramish, A. (2020). Towards a sustainable Reverse Logistics framework / typologies based on Radio Frequency Identification (RFID). Operations and Supply Chain Management 13(3), pp. 222 - 232.

Uvet, H. (2020). Importance of Logistics Service Quality in Customer Satisfaction: An Empirical Study. Operations and Supply Chain Management, 13(1), pp.1-10.

Vinodhini, A., Seethalakshmi, R., \& Sowdamini, T. (2018). Analysing the Role of Lean Management in Health Care: A Systematic Literature Review. International Journal of Mechanical Engineering and Technology (IJMET) 9(7), pp. 303-312.

Wieland, A., Handfield, R., \& Durach, C. (2016). Mapping the Landscape of Future Research Themes in Supply Chain Management. Journal of Business Logistics, 37(3), pp. 1-8.

Wieland, H., Hartmann, N. N., \& Vargo, L. (2017). Business models as service strategy. Academy of Marketing Science, 45, pp. 925 - 943

Youngblood, M. D. (2003). The Vakakaris: Following the March of Tradition in Western India. Critical Asian Studies, 35(2), pp.14.

Dr. Kumaraguru Mahadevan holds a Ph.D. and an MBA from the University of Western Sydney, Australia. In addition, he holds a Bachelor of Science in Production Engineering from Leeds Beckett University, UK, a Graduate Diploma in Technological Economics from the University of Stirling, Scotland, and a Graduate Diploma in Marketing Management from the Macquarie Graduate School of Management (MGSM). Dr. Mahadevan has held operations management, supply chain management, program management, and consulting positions at Canon Australia, Nortel Networks, LG Consumer Electronics, BTR Nylex, and Sydney Water Corporation. He has taught Supply Chain Management, Operations Management, Strategic Management, Quality Management, Logistics Management, Design It and Entrepreneurship and Business Development at the University of Wollongong, University Western Sydney and Central Queensland University at undergraduate and postgraduate levels. He has published a number of journal papers and presented papers in supply chain management at the BAM, EURAM, ANZAM, and QIK conferences. 